\title{
Design of stirling engine operating at low temperature difference
}

\author{
Josef Sedlák ${ }^{1,}$, Adam Glváč ${ }^{1}$, Andrej Czán ${ }^{2, *}$ \\ ${ }^{1}$ Department of Machining Technology, Institute of Manufacturing Technology, Faculty of \\ Mechanical Engineering, Brno University of Technology, Technická 2896/2, Brno 616 69, Czech \\ Republic \\ ${ }^{2}$ Faculty of Mechanical Engineering, University of Zilina, Univerzitna 8215/1, 01026 Zilina, \\ Slovakia
}

\begin{abstract}
There are many sources of free energy available in the form of heat that is often simply wasted. The aim of this paper is to design and build a low temperature differential Stirling engine that would be powered exclusively from heat sources such as waste hot water or focused solar rays. A prototype is limited to a low temperature differential modification because of a choice of ABSplus plastic as a construction material for its key parts. The paper is divided into two parts. The first part covers a brief history of Stirling engine and its applications nowadays. Moreover, it describes basic principles of its operation that are supplemented by thermodynamic relations. Furthermore, an analysis of applied Fused Deposition Modelling has been done since the parts with more complex geometry had been manufactured using this additive technology. The second (experimental) part covers 4 essential steps of a rapid prototyping method - Computer Aided Design of the 3D model of Stirling engine using parametric modeller Autodesk Inventor, production of its components using 3D printer uPrint, assembly and final testing. Special attention was devoted to last two steps of the process since the surfaces of the printed parts were sandpapered and sprayed. Parts, where an ABS plus plastic would have impeded the correct function, had been manufactured from aluminium and brass by cutting operations. Remaining parts had been bought in a hardware store as it would be uneconomical and unreasonable to manufacture them. Last two chapters of the paper describe final testing, mention the problems that appeared during its production and propose new approaches that could be used in the future to improve the project.
\end{abstract}

Keywords: Stirling engine, Stirling thermodynamic cycle, additive method, rapid prototyping, fused deposition modelling, 3D print

\section{Introduction}

A Stirling engine was officially presented to the public on $27^{\text {th }}$ September 1816 , when twenty-six-years-old Scottish farmer Robert Stirling (1790-1878) patented his discovery under the number 4081. In that era this marvelous device represented an alternative to a steam engine, which was preferred type of driving during and long after the Industrial

* Corresponding author: andrej.czan@fstroj.uniza.sk

Reviewers: Ivan Kuric, Richard Pastirčák 
Revolution. The fact that the machine had been patented eight years before the Sadi Carnot's monograph "Reflections on the Motive Power of Fire and on Machines Fitted to Develop that Power" was published confirms Robert's mastery of thermos-dynamical principles long before any comprehensive heat-engine theory existed [1]. The original patent actually specifies two separate discoveries. The first part and the principle number one was so-called "economizer"- a device nowadays known as a regenerator $[2,3]$. This was definitely a very significant invention and has been used until nowadays not only in the Stirling engines, but also in many other devices. The original description of the regenerator speaks about a space filled with "successive layers of plates of the thinnest iron in use, pierced with holes.....kept at a distance of two or three times of their own thickness from one another" [2]. The purpose of the regenerator is to act as a temporary heat storage element, so that as hot and cold gas is passed back and forth between the regenerator, heat is removed from the gas and then put back into it. This reduces the amount of heat needed to be transferred by the heat exchangers and increases dramatically the overall efficiency of the engine. The second part of the patent was the engine itself, which was presented as "A Closed-Cycle Air Engine", using the economizer to "diminish the consumption of fuel" [2]. Devices that were based on the principle of Stirling's patent, were being manufactured in a great variety of shapes and sizes until the turn of the centuries. They broke through thanks to their simplicity, safety, a silent operation and a possibility to be powered by any type of the fuel. Compared with the steam engines, they were environmentally-friendly and their efficiency was significantly higher, which was the main reason of their fast grow $[2,3]$. In the course of the $19^{\text {th }}$ century and at the beginning of the $20^{\text {th }}$ century, Stirling engines were manufactured for a variety of applications like pumping water for livestock, on the railways or to supply the water to municipalities [2]. Back then its development was quite limited by the metallurgical possibilities of the era. For this reason, as well as due to its higher weight it has been slowly replaced by recently developed and fast-growing internal combustion and an electric motor [2, 3, 4]. However, nowadays it is experiencing kind of renaissance thanks to its characteristics, which are irreplaceable by any other type of drive. At present the manufacturers can use modern materials to build the engine, therefore it can work under higher pressures and higher temperature differences, which makes it far more effective and powerful than it used to be. The most prominent of European companies is company Solo Stirling $\mathrm{GmbH}$, a German company which is engaged in the production of cogeneration units. The cogeneration unit made by this concern can achieve a power of $7.5 \mathrm{~kW}$ at the pressure of $13 \mathrm{MPa}$ with the efficiency of $24 \%$. The device is filled with helium with a temperature rising up to $650^{\circ} \mathrm{C}$ in operation. A service interval is 5,000-8,000 hours and normally it is necessary to change only an oil and fill the cylinders with helium [3]. The leader in a development and production of Stirling engines is Swedish company cKockums $\mathrm{AB}$, which has been focused to the development and production of high-performance power units for submarines. These have been powered by flawless engines with an output of 75 $\mathrm{kW}$. Use of the Stirling engine in the submarine's power unit is appropriate especially due to its silent operation and absence of vibrations (submarines become more difficult to be spotted). In addition, the unit does not require any air for its operation and is surrounded by water from all sides, which makes the cooling very simple and effective [3].

\section{Parts and modifications of Stirling engine}

The Stirling engine consists of 4 main parts that are indispensable for its operation. In the Fig. 1 there is a simple diagram of the engine developed by Robert Stirling. In this case, the regenerator and the cooler is separated from the engine body, however it does not have to be always like that. The function of heat exchangers is to supply heat and create two poles with two different temperatures $[2,5]$. A displacer moves a gas between a hot side and a 
cold side of the engine evenly which warms it up and cools it down periodically [2, 5]. This ensures a cyclic expansion and a compression of the gas. The periodical expansion and compression of the gas move a power piston, that transmits work to a driven mechanism of the machine $[2,5]$. The most sophisticated part of the Stirling engine is the regenerator. It is usually made of a conductive material and works as a temporary storage of the heat. The regenerator can quickly take the heat from the warm gas that flows through it and releases it back right at the moment when it starts to flow in the opposite direction. The result is a significant increase of a device efficiency. John Ericsson stressed the regenerator importance, by his equation: “...We will show practically that bundles of wire are capable of exerting more force than shiploads of coal..." (Said in 1855) [2].

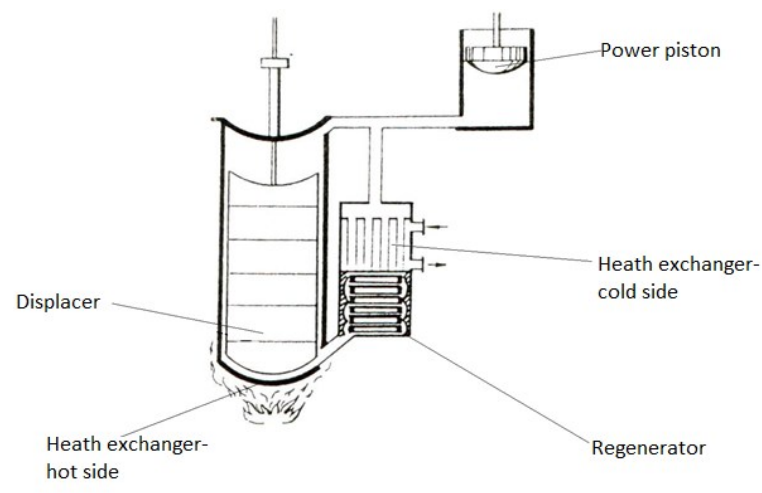

Fig. 1. Drawing of Engine Developed by Stirling Brothers in 1840 [1]

There are 3 different modifications of the engine and are usually marked by letters of Greek alphabet $\alpha, \beta$ and $\gamma[1,2,3,5]$. They all are based on the same principle, which is shown in the Fig. 1. They only differ from each other by an arrangement and shape of the individual components.

The $\alpha$ configuration has two pistons, which are stored in two separate cylinders. These are connected to the heater, regenerator and cooler. From a mechanical point of view this is a simple configuration that stands out for its high ratio of performance to the cylinders volume. Its disadvantage is that both pistons must be sealed against a leakage of gas, which is a difficult task particularly in the case of the piston that works on the hot part of the engine $[1,2,3,5]$. For the configuration $\beta$ it is typical that the displacer and the power piston share only one cylinder. Therefore, it is a quite compact design, which stands out thanks to its small dead volume (the volume of gas that does not take part in the cycle). From the mechanical point of view, it is a very simple device, since the displacer and power piston are both connected to the same point at a crankshaft. The only complication is that the displacer's rod, which connects it to the shaft, passes through the power piston. This produces higher demands on the sealing of the gas in the cylinder $[1,2,3,5]$. The $\gamma$ and the $\beta$ configuration are very similar. The only difference is that the displacer and the power piston of the modification $\gamma$ are stored in two separate cylinders. This minimalizes demands on the sealing of the gas. The modification is only suitable for very small engines, which power is in hundreds of Watts $[1,2,3,5]$. However, in comparison with others, this configuration can be built quite easily from cheap materials using exclusively simple hand tools. If the engine is designed ingeniously, it is possible to run it even when the temperature difference between two sides of the heat exchanger is almost imperceptible. Because of the use of the ABS plastic as the construction material, this is one of the main requirements for this project. 


\section{Thermal efficiency of engine with configuration $y$ which uses Stirling cycle for its operation}

A special characteristic of the modification $\gamma$ is that the cylinder that stores the power piston is often located at the cold side of the engine. Therefore, there is always a small amount of the unheated gas in the cylinder, even after the stage of isochoric heating. To simplify a calculation, it is often necessary to make an assumption that the temperature of the unheated gas equals the temperature of the cold side of the heat exchanger [5].

A total amount of the working gas in the cylinder can be calculated using the following equation:

$$
\mathrm{V}_{\text {total }}=\mathrm{V}_{\text {hot }}+\mathrm{V}_{\text {cold }} \quad[\mathrm{m} 3]
$$

Where: $\quad \mathrm{V}_{\text {total }}\left[\mathrm{m}^{3}\right]-$ is the total volume of the working gas,

$\mathrm{V}_{\text {hot }}\left[\mathrm{m}^{3}\right]$ - is the volume of the heated working gas,

$\mathrm{V}_{\text {cold }}\left[\mathrm{m}^{3}\right]$ - is the volume of the unheated working gas.

A total amount of the substance can be calculated using the following equation:

$$
\mathrm{n}_{\text {total }}=\mathrm{n}_{\text {hot }}+\mathrm{n}_{\text {cold }} \quad[\mathrm{mol}]
$$

Where: $\quad \eta_{\text {total }}[\mathrm{mol}]-$ is the total amount of the working gas,

$\eta_{\text {hot }}[\mathrm{mol}]$ - is the amount of the heated working gas,

$\eta_{\text {cold }}[\mathrm{mol}]$ - is the amount of the unheated working gas.

The ideal gas equation for the working gas in the point 3 of a $\mathrm{p}-\mathrm{V}$ diagram, which is shown in the Fig. 2, has the following form:

$$
\mathrm{n}_{\text {total }}=\frac{\mathrm{pV}_{\text {hot }}}{\mathrm{RT}_{\text {hot }}}+\frac{\mathrm{p}\left(\mathrm{V}_{\text {total }}-\mathrm{V}_{\text {hot }}\right)}{\mathrm{RT}_{\text {cold }}} \quad[\mathrm{mol}]
$$

Where: $\quad \mathrm{p}[\mathrm{Pa}]$

$$
\begin{aligned}
& \mathrm{R}\left[\mathrm{J} \cdot \mathrm{K}^{-1} \cdot \mathrm{mol}^{-1}\right] \\
& \mathrm{T}_{\text {hot }}[\mathrm{K}] \\
& \mathrm{T}_{\text {cold }}[\mathrm{K}]
\end{aligned}
$$

- is the pressure of the working gas,

- is a gas constant,

- is the temperature of the heated working gas,

- is the temperature of the heated working gas.

From the p-V diagram shown in Fig. 2, it is obvious that the work done during the expansion of the isothermal expansion is equal to the surface under the curve $\mathrm{W}_{\mathrm{e}}$ between the points 3 and 4 . Because there are no losses to consider, the work done for each part of the cycle is the same as heat added to the gas:

$$
\mathrm{W}_{\mathrm{e}}=\mathrm{Q}_{\mathrm{e}}=\int_{3}^{4} \mathrm{pdv} \quad[\mathrm{J}]
$$

Where: $\quad \mathrm{W}_{\mathrm{e}}[\mathrm{J}] \quad$ - is the work done during the isothermal expansion, $\mathrm{Q}_{\mathrm{e}}[\mathrm{J}] \quad$ - is heat added to the gas.

By expressing the pressure $p$ used in the equation number (3), and by its substitution in equation (4), the following relation can be obtained:

$$
\mathrm{Q}_{\text {expansion }}=\mathrm{W}_{\mathrm{e}}=\mathrm{n}_{\text {total }} \mathrm{RT}_{\text {cold }} \int_{3}^{4} \frac{\mathrm{dv}}{\mathrm{V}_{\text {total }}-\mathrm{V}_{\text {hot }}\left(\frac{\mathrm{T}_{\text {hot }}-\mathrm{T}_{\text {cold }}}{\mathrm{T}_{\text {hot }}}\right)}
$$


The compression ratio of the engine is the quotient of the maximum and the minimum volume of the system in the cycle. In this case:

$$
\varepsilon=\frac{\mathrm{V}_{4}}{\mathrm{~V}_{3}} \quad[-]
$$

Where: $\quad \varepsilon[-] \quad-$ is the compression ratio,

$\mathrm{V}_{4}\left[\mathrm{~m}^{3}\right] \quad$ - is the volume of the working gas in the point 3 ,

$\mathrm{V}_{3}\left[\mathrm{~m}^{3}\right] \quad-$ is the volume of the working gas in the point 4 .

By integrating of the expression (5) and using the equation for the compression ratio (6), it is possible to derive an equation to calculate heat added to the system during the isothermal expansion:

$$
\mathrm{Q}_{\mathrm{e}}=\mathrm{W}_{\mathrm{e}}=\mathrm{n}_{\text {total }} \mathrm{RT}_{\text {cold }} \ln \frac{\varepsilon-\frac{\mathrm{T}_{\text {hot }}-\mathrm{T}_{\text {cold }}}{\mathrm{T}_{\text {hot }}}}{1-\frac{\mathrm{T}_{\text {hot }}-\mathrm{T}_{\text {cold }}}{\mathrm{T}_{\text {hot }}}} \quad[\mathrm{J}]
$$

Furthermore, it is necessary to derive the equation which would define the work that performs the gas in the stage of the isothermal compression. This action takes place between points 1 and 2 in the Fig. 2 . At this stage, there is no heated gas in the system. Therefore the temperature equals to $\mathrm{T}_{\text {cold. }}$. The gas equation for this stage has the following form:

$$
\mathrm{pV}_{\text {total }}=\mathrm{n}_{\text {total }} \mathrm{RT}_{\text {cold }} \quad[\mathrm{Pa} \cdot \mathrm{m} 3]
$$

The work that is necessary for the compression of the working gas during the isothermal compression is equal to the surface under the curve 1 and 2 in the $\mathrm{p}-\mathrm{V}$ diagram in the Fig. 2. Substituting the pressure $\mathrm{p}$ by (8):

$$
\mathrm{W}_{\text {compresion }}=\int_{1}^{2} \mathrm{pdv}=\mathrm{n}_{\text {total }} \mathrm{RT}_{\text {cold }} \int_{1}^{2} \frac{\mathrm{dv}}{\mathrm{V}_{\text {total }}}
$$

The total net work obtained in one cycle $\mathrm{W}_{\text {net }}$ is the sum of the work done during the compression and the following expansion of the gas:

$$
\mathrm{W}_{\text {net }}=\mathrm{W}_{\mathrm{e}}+\mathrm{W}_{\mathrm{c}} \quad[\mathrm{J}]
$$

Where: $\quad \mathrm{W}_{\text {net }} \quad-$ is the total net work obtained in once cycle.

Substituting (7) and (9) to (10):

$$
\mathrm{W}_{\text {net }}=\mathrm{n}_{\text {total }} \mathrm{RT}_{\text {cold }} \ln \frac{\varepsilon-\frac{\mathrm{T}_{\text {hot }}-\mathrm{T}_{\text {cold }}}{\mathrm{T}_{\text {hot }}}}{1-\frac{\mathrm{T}_{\text {hot }}-\mathrm{T}_{\text {cold }}}{\mathrm{T}_{\text {hot }}}}-\mathrm{n}_{\text {total }} \mathrm{RT}_{\text {cold }} \ln \varepsilon
$$

The total cycle efficiency is defined as the ratio between the total net work output and the total heat input. Substituting $\mathrm{W}_{\text {net }}$ by (7) and $\mathrm{Q}_{\mathrm{e}}$ by (11) the following equation is obtained: 


$$
\eta_{\mathrm{t}, \gamma}=\frac{\mathrm{W}_{\text {net }}}{\mathrm{Q}_{\mathrm{e}}}=1-\frac{\mathrm{n}_{\text {total }} \mathrm{RT}_{\text {cold }} \ln \frac{\varepsilon-\frac{\mathrm{T}_{\text {hot }}-\mathrm{T}_{\text {cold }}}{\mathrm{T}_{\text {hot }}}}{1-\frac{\mathrm{T}_{\text {hot }}-\mathrm{T}_{\text {cold }}}{\mathrm{T}_{\text {hot }}}}-\mathrm{n}_{\text {total }} \mathrm{RT}_{\text {cold }} \ln \varepsilon}{\ln \left(\varepsilon-\frac{\mathrm{T}_{\mathrm{h}}-\mathrm{T}_{\mathrm{c}}}{\mathrm{T}_{\mathrm{h}}}\right)-\ln \left(1-\frac{\mathrm{T}_{\mathrm{h}}-\mathrm{T}_{\mathrm{c}}}{\mathrm{T}_{\mathrm{h}}}\right)}
$$

Where: $\quad \eta_{\mathrm{t}, \gamma}-$ is the thermal efficiency of the modification $\gamma$.

Or more simplified (12):

$$
\eta_{\mathrm{t}, \gamma}=\frac{\mathrm{W}_{\text {net }}}{\mathrm{Q}_{\mathrm{e}}}=1-\frac{\ln \varepsilon}{\ln \left(\varepsilon-\frac{\mathrm{T}_{\mathrm{h}}-\mathrm{T}_{\mathrm{c}}}{\mathrm{T}_{\mathrm{h}}}\right)-\ln \left(1-\frac{\mathrm{T}_{\mathrm{h}}-\mathrm{T}_{\mathrm{c}}}{\mathrm{T}_{\mathrm{h}}}\right)}
$$
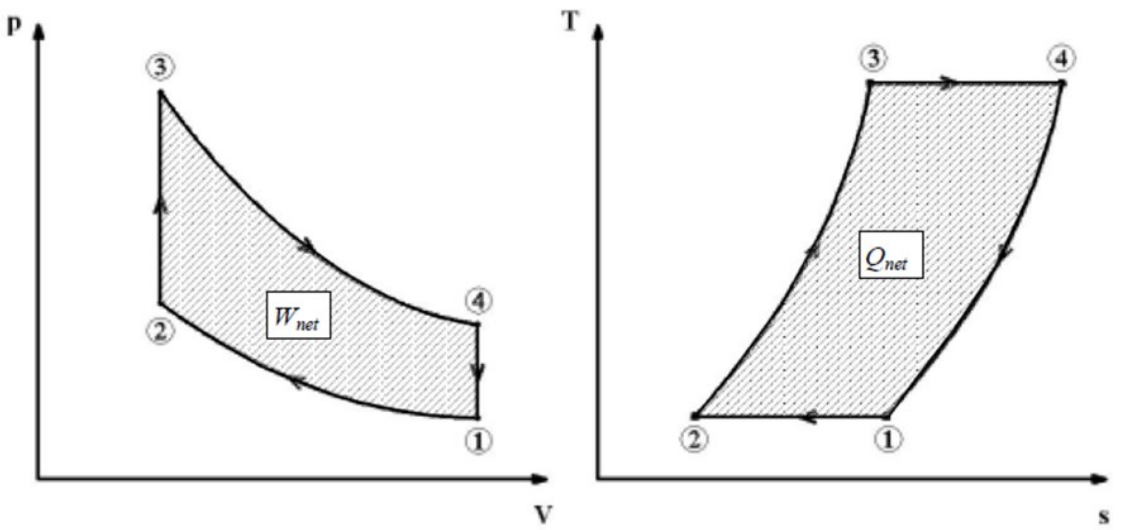

Fig. 2. p-V and T-s Diagram for Ideal Stirling Cycle during Isothermal Compression [2]

Fig. 3 and Fig. 4 have been created using the equation (13). Even though this relation is valid only for the ideal cycle, it expresses two essential facts about the $\gamma$ modification of the engine:

- When the compression ratio rises, the thermal efficiency of the engine decreases.

- When the temperature difference rises, the efficiency increases logarithmically.

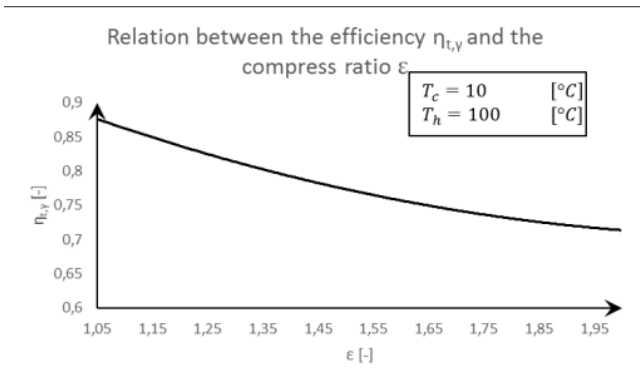

Fig. 3. Relationship between Efficiency and Compress Ratio [3]

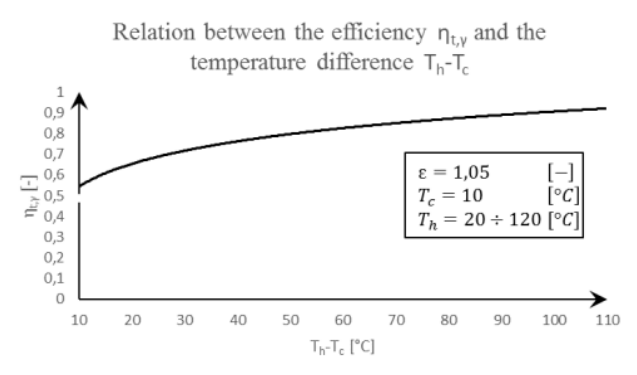

Fig. 4. Relationship between Efficiency and Temperature Difference [3] 


\section{Design of Stirling engine}

The aim of this project is to make a model of the engine that uses the principle of the Stirling cycle for its operation. All parts with the complex shape are manufactured using the additive technology Fused Deposition Modeling (FDM). Remaining parts are either produced using hand tools or simple industrial machines, or bought in the hardware store. These are mainly screws, sealing and wires, which would be uneconomical to manufacture, or the sheets of metals coming to a direct contact with augmented heat during the engines operation. Because the ABS plus plastic has low resistance against high temperatures, the whole concept is designed to work at the temperature difference lower than $50{ }^{\circ} \mathrm{C}$.

The idea of the whole design is to make the compact engine that would be extremely easy to assemble and disassemble and would be built from the parts that can be easily replaced in a case of optimization. It is intended that the engine would serve for training purposes, therefore there is an effort to create a structure that would withstand rather incautious treatment. For this reason, it is not expected to achieve significant performance or high revolutions. The goal is to make the engine strong enough to be able to stay in the operation as long as it is possible at extremely low temperature difference. Digital visualization of the model is shown in the Fig. 5 and Fig. 6.

The engine has been composed of 11 parts produced by the technology FDM. Low thermal conductivity of the ABS plus plastic is beneficial for the parts like the displacer or cylinder. For the rest of the printed parts, its thermal conductivity does not affect their proper function.

In cases, where material properties of the ABS plus plastic impede the proper function of the parts are designed to be as simple as possible, so they could be manufactured using hand-tools or simple industrial machines. Those are the aluminum plates forming sides of the heat exchanger and have to be made out of materials with a high thermal conductivity. It is decided to use a $2.5 \mathrm{~mm}$ thick aluminum sheet that is shaped by shearing. The work piston and the cylinder are machined using a lathe. It is not possible to find more adequate technology, because the power piston has to be stored in the cylinder with high precession so it can move from end to end with minimal friction.

The remaining parts that formed the engine are standardized and available in the hardware store. These are a set of M3 size screws of various lengths, nuts, washers, sealing, wires, bearings and a shaft.

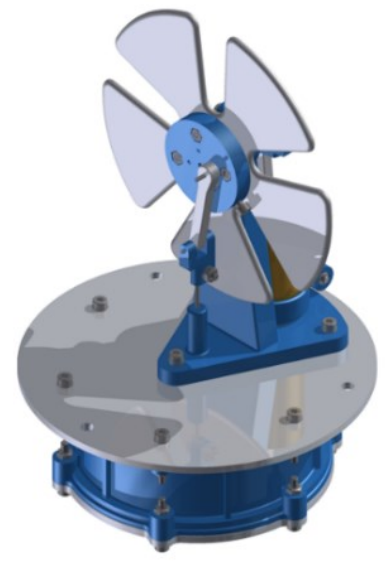

Fig. 5. Digital Visualization of Stirling Engine [6]

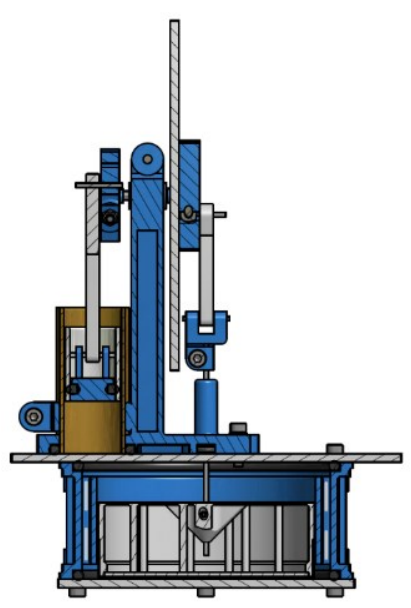

Fig. 6. Cut through Model [6] 


\section{Manufacturing of model}

The digital model is created in a parametric modeler Autodesk Inventor. All parts are saved in a stereolithography $(*$.stl) format afterwards. The *.stl format is the standard format for a majority of rapid prototyping technologies. A volume of parts saved in the *.stl format is a compound of an unorganized mesh of triangular shaped surfaces $[7,8,9,10]$. The position of each of these triangles is given by the coordinates $\mathrm{X}, \mathrm{Y}$, and $\mathrm{Z}$ of each of its vertices and a normal vector to its surface. The direction of the vector determines the orientation of the triangle. It defines the side of the triangle that would be oriented outwards of parts body [7, $8,9]$. The next essential finding is that a geometry of the *.stl part is always an approximation of the shape created by the parametric modeler. How close the shape of the *.stl part would get to the shape of the parametric model is determined by the density of the triangular mesh $[9,11]$. When the model is converted to the *.stl format, various types of defects can be generated in the mesh. The most common are flipped triangles, boundary edges, bad edges, holes, shells, intersecting or overlapping triangles $[7,9,12]$. The overwhelming majority of defects that are originated during the export of the parts to the *.stl format, are successfully eliminated using the software MiniMagics. Few overlapping triangles are not eliminated in a case of the parts with the most complex geometry. However, this type of defects does not affect the final result of a manufacturing process, therefore it is possible to ignore it $[10,11,12]$.

After all the critical defects are eliminated, all the parts are opened one by one in the software called CatalystEx. CatalystEx is the software that communicates with all kinds of 3D printers from series Dimension made by the leading manufacturer of 3D printers Stratasys $[13,14]$. The software is able quickly and easily open 3D drawings of parts, prepare them for printing and send a print command to the printer to create the part. The software is used to scale the parts and to place them on the desired place of a pad subsequently. Correct orientation of each part in a build chamber is chosen afterwards. Finally, the support material, which prevents a collapse of the model, is added (this process is highly automated and works wonderfully).

When all these adjustments are done, estimated print time is calculated and the print command is sent to the printer. The printing process consists of two steps. All parts except the stand of the engine are printed in the first step. Printing of these 10 parts take 11 hours and 28 minutes. $101.79 \mathrm{~cm}^{3}$ of the building material and $45.65 \mathrm{~cm}^{3}$ of the support material is used. The Fig. 7 shows parts in the middle of the printing process and the Fig. 8 shows the parts when the printing is completed. The black colored support material is still visible attached to the model.

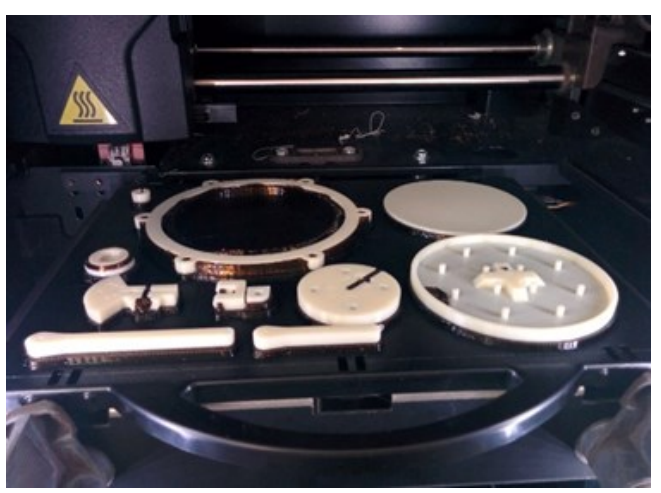

Fig. 7. Parts in Middle of Process

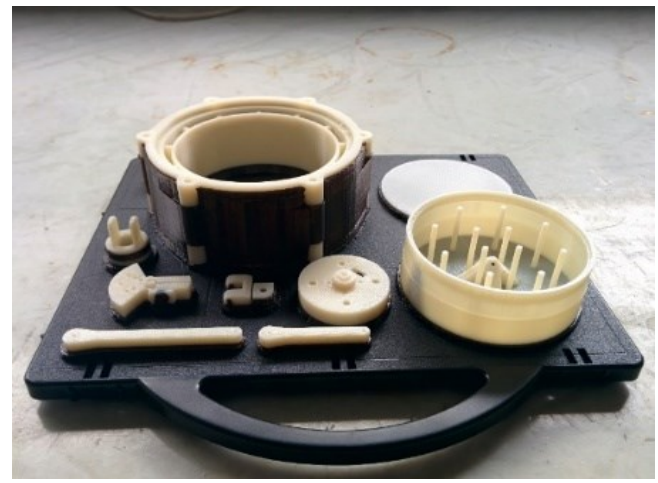

Fig. 8. Parts after Successful Printing 
In the second step the stand of the engine is printed. As it is the most complex part from the whole project, it take 4 hours and 42 minutes to print it. $38.7 \mathrm{~cm}^{3}$ of the building material and $14.42 \mathrm{~cm}^{3}$ of the support material are used.

When the printing of the parts has been completed, all parts are separated from the pad and are immersed into the ultrasonic cleaner VGT1990QT from the manufacturer GT SONIC with the goal to dissolve the support material. The active substance is prepared by mixing WaterWorks Soluble Concentrate P400SC from Stratasys and water. After the parts have been removed from the cleaners tub, smoothness of surfaces is satisfactory. Therefore only the outer side of the displacer and the inner side of the cylinder have to be finished afterwards. These surfaces are sanded to achieve a smooth touch in the contact area. Sandpapers of roughness P400 and P600 are used for the job. After the surfaces have been sanded, an acrylic spray paint is applied to cover minor bumps. Sanded surfaces are satisfactory and the displacer could move along the cylinder without rubbing its inner side. All the holes presented at the model have been purposely undersized when the model has been designed. Therefore, the last part of this stage is to adjust them to the wanted size. Finally, all the parts are assembled. The Fig. 9 shows the engine after the assembly.

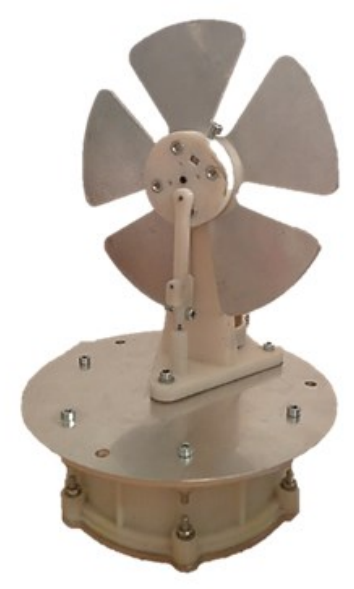

Fig. 9. Fully Assembled Engine

\section{Discussion}

Once the model was assembled, tests were performed. The warm side of the heat exchanger was placed on the cup filled with hot water. To ensure the sufficient temperature difference between the poles of the motor, ice was laid on the cold side. In this state, the engine was left for two minutes to allow the gas to get warm. After that, the engine was started giving the light spin to the flywheel. The flywheel made a couple of turns, but then it started to slow down gradually until a standstill. The engine while in work was too loud, which was due to the friction between the parts of the engine. The model was subsequently dismantled. The reason for the increased friction could be identified. The wire that connects the fork with the displacer was damaged. The wire was straightened and lightly sanded. The airtightness of the adhesive bond between the two parts of the displacer was tested as well. After dipping the displacer under water to a depth of $20 \mathrm{~cm}$ no leakage of the gas was observed. The airtightness was therefore evaluated as sufficient. Subsequently, the model was re-assembled and ready for the second test.

During the second test the engine was significantly quieter, but it failed to run smoothly. The reason for the failure was a high mass of the aluminum flywheel. It has been replaced 
by gluing 3 compact discs together, which together weigh 45 grams. Compared to the original aluminum flywheel it was $40 \%$ lighter.

In the third test the flywheel was spun before and after heating. It could be observed that the warm engine makes more spins as the cold engine. This difference was not observed when the aluminum flywheel was used. It could therefore be postulated that the weight of the flywheel has the significant influence on engine performance and that the weight of 45 grams is more appropriate than the weight of 75 grams.

After the third failed test the overall airtightness of the engine was tested. The test was performed by raising the power piston to its upper position and its free falling. The piston fell to its lowest position at a steady rate. This process was repeated 10 times and the average time of a descent of 0.98 seconds was measured. Expected time providing good sealing were 4 seconds. It was therefore clear that the engine was not sufficiently sealed. For further measurements the engine was dismounted, the displacer was removed and the hole in the stand has been blocked. The airtightness test was carried out again. In the second measurement average time of the descent was $1.32 \mathrm{~s}$. An additional significant leakage of the gas took place in the area between the power piston and the cylinder. It was found that abrasive wearing of the outer wall of the working piston took place and has reduced the size of the piston to such an extent that there was now a gap large enough for air to leak. The reason for abrasive wearing was the ill centered piston in the cylinder.

\section{Conclusion}

Even when several modifications were done, the steady operation of the engine was not achieved. Main factors that impede the proper function of the device are:

- As the power piston was not placed in the cylinder correctly, it rubbed against the inner side of the cylinder. Therefore the contact surfaces suffered a slight damage by an abrasion.

- The cylinders were not sealed sufficiently and the gas leaked from the engine excessively.

- The original aluminum flywheel was too heavy to operate.

Nevertheless, the model is great for further editing and enhancement, which should lead to eliminate deficiencies of the first prototype. The more precise assembly should eliminate first two factors. To reduce the weight of the flywheel it is possible to choose the material with the lower density (e.g. the ABS plastic), or by implementing a number of lightening holes into the shape of the aluminum flywheel. Ones the engine reaches the steady operation, it will be suitable for experiments that would test different types of regenerators and its influence to engines performance.

Despite the fact that the steady operation was not achieved, the model would serve for educational purposes to demonstrate the mechanism of the Stirling engine and to familiarize the audience with the principle of its operation.

This article was supported and co-financed from a specific research FSI-S-16-3717 called "Research in Field of Modern Production Technologies for Specific Applications".

\section{References}

1. J. Hromádko, Speciální spalovaci motory. (Česká zemědělská univerzita, Praha, 1. vyd., 151 p., ISBN 978-80-213-2168-7, 2011) 
2. C. Lloyd, A low temperature differential Stirling engine for power generation. Cantebury. Master's Thesis. University of Canterbury. Department of Electrical and Computer, available at: http://hdl.handle.net/10092/2916 (2009)

3. J. Blaha, Stirlingův motor. 80 p., Vysoké učení technické v Brně. Fakulta strojního inženýrství. Ústav automobilního a dopravního inženýrství. Vedoucí diplomové práce doc. Ing. Zdeněk KAPLAN, CSc. (2008)

4. Kongtragool, Bancha a Somchai WONGWISES, A review of solar-powered Stirling engines and low temperature differential Stirling engines. Renewable and Sustainable Energy Reviews [online] 7 (2), 131-154 [seen 22.3.2015]. DOI: 10.1016/s13640321(02)00053-9, ISSN 1364-0321, Available at: http://linkinghub.elsevier.com/retrieve/pii/S1364032102000539 (2003)

5. D.G. Thombare, S.K. Verma, Technological development in the Stirling cycle engines. Renewable and Sustainable Energy Reviews [online] 12 (1), 1-38 [seen 2015-03-22] DOI: $\quad 10.1016 /$ j.rser.2006.07.001. ISSN 13640321. Available at: http://linkinghub.elsevier.com/retrieve/pii/S1364032106000906 (2008)

6. Autodesk Inc. C2015, 3D CAD Sotware: Inventor 3D CAD, Autodesk: 3D Design, Engineering \& Entertainment Software. [online] [seen 2015-04-22] Available at: http://www.autodesk.com/products/inventor/overview (2015)

7. C. Chua, K. Leong, C. Lim, Rapid prototyping: principles and applications. (New Jersey: Word Scientific, C2010, p. XXV, 512 p. 8. MCAE SYSTEMS, spol. s.r.o., Kư̌im, ČR. Dimension uPrint (2010)

8. J. Sedlak, D. Rican, M. Piska, Study of Materials Produced by Powder Metallurgy Using Classical and Modern Additive Laser Technology. Procedia Engineering 2015 (1), 1232-1241, ISSN 1877-7058 (2015)

9. J. Sedlak, M. Ptackova, J. Nejedly, M. Madaj, J. Dvoracek, J. Zouhar, M. Piska Material Analysis of Titanium Alloy Produced by Direct Metal Laser Sintering. International Journal of Metal Casting 7 (2), 43-50, ISSN 1939-5981 (2013)

10. J. Novak-Marcincin, M. Janak, L. Novakova-Marcincinova, Increasing of Product Duality Produced by Rapid Prototyping Technology. Manufacturing Technology 12 (12), 71-75, ISSN 1213-2489 (2012)

11. J. Sedlak, M. Slany, Z. Fiala, A. Jaros, Production Method of Implant Prototype of Knee-Joint Femoral Component. Manufacturing Technology 15 (2), 195-204, ISSN 1213-2489 (2015)

12. Ch. Ch. Kuo, L. Ch. Liu, W. F. Teng, H. Y. Chang, F. M. Chien, S. J. Liao, W. F. Kuo, Ch. M. Chen, Preparation of starch/acrylonitrile-butadiene-styrene copolymers (ABS) biomass alloys and their feasible evaluation for $3 D$ printing applications. Composites Part B: Engineering 86, 36-39. DOI: 10.1016/j.compositesb.2015.10.005. ISSN 13598368. Available at: http://linkinghub.elsevier.com/retrieve/pii/S1359836815005983 (2016)

13. uPrint SE. Stratasys Ltd. [online] [seen 2015-05-17] Available at: http://www.stratasys.com/3d-printers/idea-series/uprint-se (2015)

14. FDM Technology. Stratasys Ltd. [online] [seen 2015-05-17] Available at: http://www.stratasys.com/3d-printers/technologies/fdm-technology (2015) 